DOI: https://doi.org/10.15688/jvolsu4.2016.4.10

UDC 656(091)(470.45)

Submitted: 19.01.2016

LBC 63.3(2Poc-4Вог)5-2

Accepted: 12.05 .2016

\title{
ECONOMIC DEVELOPMENT OF SAREPTA DISTRICT OF THE TSARITSYN COUNTY AT THE TURN OF THE 19TH-20TH CENTURIES ${ }^{1}$
}

\author{
Aleksandr E. Parfenov \\ Historical, Ethnographic, and Architectural Museum-Reserve "Old Sarepta", \\ Volgograd, Russian Federation
}

\begin{abstract}
The article shows the process of the industrial development of Sarepta district (now the southern part of Volgograd) at the turn of the 19th and 20th centuries. By the end of the 19th century the Sarepta district comprised 17 production entities. The majority of them were small workshops that manufactured various household goods and had from 5 to 10 workers. Besides, Sarepta had a larger industrial enterprise - the Mustard Factory of the Glitsch - which was known throughout Russia for the high quality of its produce. Agriculture played a minor role in Sarepta district. The population of Sarepta district amounted to about 1800 people in 1894. It comprised landowners, small industrialists, and their hired workers. The late 19th and early 20th centuries saw a rapid industrial development of the area. The first stage of the process was the building of the Tsaritsyn- Tikhoretskaya railway line. It connected the Kuban wheat-growing region with central areas of Russia. A 13-kilometres long section of the railway line passed through Sarepta district. Near Sarepta a station, a locomotive depot, and repair workshops were built in 1895-98. In 1901 the railway line and station were supplemented with a large cargo port on the Volga near Sarepta. The creation of the large transport hub sharply raised the economic significance of Sarepta district. Social and demographic characteristics of the area also changed dramatically. Due to the inflow of workers to the station and port, the district population nearly doubled and the ratio of proletariat raised sharply.
\end{abstract}

Key words: Sarepta district, industrial development, railway line, port, population growth, proletariat.

УДК 656(091)(470.45)

ББК 63.3(2Рос-4Вог)5-2

Дата поступления статьи: 19.01.2016

Дата принятия статьи: 12.05.2016

\section{ЭКОНОМИЧЕСКОЕ РАЗВИТИЕ САРЕПТСКОЙ ВОЛОСТИ ЦАРИЦЫНСКОГО УЕЗДА В КОНЦЕ ХІХ - НАЧАЛЕ ХХ ВЕКА ${ }^{1}$}

\author{
Александр Евгеньевич Парфенов \\ Историко-этнографический и архитектурный музей-заповедник «Старая Сарепта», \\ г. Волгоград, Российская Федерация
}

Аннотация. В статье рассматривается процесс экономического развития Сарептской волости Царицынского уезда на рубеже XIX-XX веков. Основной частью этого процесса было проведение через территорию волости железной дороги Царицын - Тихорецкая со строительством крупной станции и депо, а также сооружение на берегу Волги грузового порта. Формирование крупного транспортного узла значительно повысило хозяйственное значение Сарептской волости в масштабе всей страны, так как он позволил связать между собой Центральный промышленный район, Прикамье, Кубань, Северный Кавказ и каспийский регион. Промышленное развитие Сарептской волости также повлекло серьезные изменения ее социально-демог- 
рафической характеристики. За первое десятилетие XX в. население волости выросло почти вдвое, при этом в его составе резко увеличилась доля пролетариата.

Ключевые слова: Сарептская волость, промышленное развитие, железная дорога, порт, рост населения, пролетариат.

В конце XIX - начале XX в. Царицын переживал период активного экономического развития. В это же время в 30 км от города, в Сарептской волости Царицынского уезда, начал формироваться промышленный район, который впоследствии был включен в Сталинград и составил его южную индустриальную часть.

Развитие Сарептской волости было связано со строительством железной дороги Царицын - Тихорецкая во второй половине 1890-х годов. К этому времени промышленность Сарепты была представлена в основном частными и несколькими общинными предприятиями пищевой и перерабатывающей отраслей. В 1894 г. в поселке было 17 небольших мастерских с полукустарным производством, основанном на частично механизированном труде, с количеством работников от 5 до 10 человек. В их числе было 4 столярно-колесных, 2 столярно-бондарных, 3 кузнечно-слесарных, 3 медных, 2 сапожных, 3 портных мастерских [13, л. 38]. Также в Сарепте работали небольшая колбасная фабрика и бойня при ней, поставлявшая продукцию на местный рынок; лесопильный завод братьев К.Е. и Ф.П. Бауэров. Были в Сарепте и торговые заведения. Это трактир с винным погребом, москательная лавка, булочная, мануфактурно-бакалейная лавка купца П.И. Бауэра, бакалейная лавка В. Гольдбаха, железо-скобяной магазин О.А. Люкштедта. Продукция этих предприятий реализовывалась в самой Сарепте, близлежащих русских, татарских селах, в калмыцких стоянках, в Царицыне. Более широкой известностью пользовалась продукция пекарни и кондитерской Меннелей, выпекавших хлеб разных сортов, булочки, пирожные, лепешки, сухари, калачи, медовые коврижки и пряники, печенье. Путешественники отмечали отличные вкусовые качества сарептских пряников, отмеченных Похвальным листом на Выставке предметов пчеловодства в Петербурге в 1893 году [10, с. 191].

На фоне этих мелких производств выделялись своими размерами кирпично-черепичная и горшечная фабрика Ниденталя с числом рабочих 50 человек, горчичный завод Кноб- лоха с числом рабочих 18 человек и объемом производства в 25000 руб., а также горчичный завод фирмы «Наследники И.К. Глич»крупнейшее предприятие Сарепты, пользовавшееся всероссийской известностью [3, с. 186187]. Оно было основано жителем этого поселка, аптекарем и естествоиспытателем Иоганном Конрадом Найцем в 1801 г., а в 1816 г. перешло к его зятю Иоганну Каспару Гличу. Благодаря кропотливой работе по совершенствованию производственных технологий и неоднократной модернизации оборудования И.К. Глич и его наследники смогли занять лидирующие позиции на российском рынкегорчицы, создав известную торговую марку «Сарептская горчица». В 1880-е гг. фабрика фирмы «Наследники И.К. Глич» ежегодно перерабатывала 4060 тыс. пудов зерна и производила 10-20 тыс. пудов горчицы и от 4 до 10 тыс. пудов горчичного масла на 70000 руб. при числе рабочих около 70 человек [3, с. 190]. Продукция фабрики находила сбыт в разных городах европейской части России, включая Москву и Петербург, некоторое количество экспортировалось. Таким образом, во второй половине XIX в. в волостном центре Сарепта работало крупное предприятие, способное конкурировать с предприятиями губернских городов.

Кроме Сарепты, в Сарептскую волость входило 6 хуторов, жители которых занимались сельским хозяйством; также в сельском хозяйстве было занято некоторое количество жителей Сарепты. Однако эта отрасль занимала второстепенное место в хозяйстве Сарептской волости. На начало ХХ в. волость занимала площадь свыше 17 тыс. га. Из них пашенные земли составляли около 3 тыс. га, сенокосные более 200 га [13, л. 38-39 об.]. Традиционно сарептяне выращивали зерновые: озимую и яровую рожь, пшеницу, овес, просо, ячмень; бобовые: горох, чечевицу, фасоль; масличные культуры: арахис, подсолнечник, горчицу; бахчевые и прочее. Урожаи зерновых в зоне засушливой степи были не выше 3-4 центнеров с гектара - самые низкие показатели по Саратовской губернии [2, с. 22]. Более прибыльными от- 
раслями сельского хозяйства являлись садоводство и виноградарство. В Сарепте имелось свыше 30 садов общей площадью до 25 га [12, л. 27]. Также жители волости занимались животноводством, разводили птицу.

Таким образом, к 1890-м гг. хозяйство Сарептской волости было представлено в основном мелкими перерабатывающими и торговыми предприятиями с числом занятых не более 10 человек при практически ничтожном значении сельского хозяйства. Крупнейшим населенным пунктом волости был ее центр - Сарепта, основанная в 1765 г. членами религиозной организации Братский Союз гернгутеров с центром в г. Гернгут (Саксония). В 1894 г. в Сарепте проживало 1700 человек [7, с. 114]. Ядром населения поселка были бывшие члены братской общины гернгутеров, ликвидированной в 1892 году. Их численность в 1894 г. составляла 347 человек и они имели статус поселян-собственников (сельских обывателей) [7, с. 114]. До административной реформы Сарепты в 1877 г. члены братской общины были единственной категорией жителей поселка, которые могли иметь в собственности недвижимое имущество. И после реформы они представляли основную часть владельцев сарептских предприятий. Другую группу населения Сарепты в количестве 760 человек составляли переехавшие туда немцы из других поволжских иностранных колоний [7, с. 114]. Небольшая их часть владела мелкими ремесленными мастерскими, но в основном они были наемными рабочими на фабриках и в мастерских, были заняты на сезонных сельскохозяйственных работах, а также устраивались работниками (конюхами, плотниками и т. д.) в дома поселян-собственников. Остальную часть населения Сарепты составляли русские, татары, калмыки, приехавшие из населенных пунктов соседних волостей для работы по найму на сарептских предприятиях и в сельском хозяйстве. Количество наемных работников было нестабильным - многие из них, особенно занятые на сезонных сельскохозяйственных работах, по окончании срока найма возвращались в свои родные дома; таким образом, численность населения Сарепты была подвержена колебаниям. Население шести хуторов Сарептской волости в количестве около 90 человек составляли немцы (как сарептские, так и приезжие из других поволжских колоний), а также сезонные работники из соседних волостей. На хуторах занимались сельским хозяйством.

Таким было социально-экономическоелицо Сарептской волости к середине 1890 -х годов. На рубеже веков в хозяйственной жизни района произошли большие перемены, которые значительно изменили его облик к началу Первой мировой войны. Началом превращения Сарептской волости в промышленный район Царицынского уезда, как уже было сказано, стало строительство железной дороги Царицын - Тихорецкая (Владикавказская железная дорога), которая связала Царицын с Кубанью и Северным Кавказом. Впервые вопрос о строительстве этой дороги был поднят еще в 1889 г. [9, л. 1]. К тому времени Царицын уже превратился в важный транспортный узел на Нижней Волге, связывавший нефтяной регион Каспия через Грязе-Царицынскую железную дорогу с центральным промышленным районом России, а богатый лесом район реки Камы - через Донскую дорогу (Царицын - Калач) с черноморскими портами. Отсутствие надежных и недорогих путей сообщения с таким важным хозяйственным регионом, как Кубань, неблагоприятно сказывалось на экономическом развитии страны.

Окончательное решение о строительстве дороги было принято в 1895 году. По плану ее начальный участок должен был пойти из Царицына на юг вдоль Волги, а в 2 верстах от Сарепты дорога резко поворачивала бы на юго-запад в направлении на Кубань. Часть трассы железной дороги, таким образом, должна была пройти по территории Сарептской волости, которая лишалась при этом значительного количества пахотной земли, лугов, садов, а также части волжского берега с рыбными угодьями. Строительство нового пути осуществляло Общество Владикавказской железной дороги. В начале июня 1896 г. агент общества по отчуждению имуществ А.В. Замковой обратился к земскому начальнику первого участка Царицынского уезда Я.Д. Молдавскому с просьбой предложить сельскому обществу Сарепты составить «приговор» с указанием цены за отчуждаемую у Сарепты землю. 19 октября того же года общественный сход сарептян принял решение об отчуждении Обществу Владикавказской железной дороги 1311 десятин за 250 тыс. руб. Под строитель- 
ство дороги были вырублены 2 десятины фруктовых садов и ликвидированы 350 квадратных саженей пашни [9, л. 5-7].

1 июля 1899 г. железная дорога длиной 502 версты и стоимостью 50 млн руб. вступила в строй. Участок дороги, пролегавший через Сарептскую волость, имел длину 13 верст. У места поворота дороги от берега Волги, в 2 верстах от поселка Сарепта, была построена станция с таким же названием. Первоначально, в 1893 1894 гг., было сооружено временное деревянное здание вокзала, в 1895-1896 гг. оно было заменено на каменное. В новом здании имелся просторный вестибюль, зал ожидания, ресторан [9, л. 22-23]. В 1895 г. при станции появилась электростанция. В 1898 г. было построено паровозное депо веерного типа на 8 канав с поворотным кругом [9, л. 22-23]. В том же году на станции были построены вагонные и колесные мастерские. В 1904 г. рядом со станцией была сооружена водонапорная башня, а на волжском берегу - водокачка. К 1914 г. депо станции Сарепта имело 18 паровозов [9, л. 110]. Между Царицыным и Сарептой было налажено пассажирское железнодорожное сообщение.

Рядом со станцией в 1895-1897 гг. были построены одно- и двухэтажные жилые дома с хозяйственными зданиями для администрации и рабочих-железнодорожников. Также сооружались объекты социальной инфраструктуры. В 1897-1899 гг. было возведено двухэтажноекирпичное здание больницы. К 1914 г. для детей железнодорожников была открыта начальная 5-классная школа с интернатом для приезжающих учащихся со станций Чапурники, Тундутово, Абганерово той же железной дороги. Построенный к 1897 г. поселок станции Сарепта представлял собой прямоугольник со сторонами приблизительно 1700 на 640 м, разбитый внугри на кварталы. Для специалистов-железнодорожников (инженерно-технический персонал) и их семей были возведено 35 домов. Кроме того, в поселке было 5 так называемых казарм (общежитий) для неквалифицированных работников: грузчиков, дворников, возчиков и т. д. В отдельных домах жили начальник депо и начальник дистанции. Во дворе каждого дома был оборудован сарай и ледник, в дома был проведен водопровод [1]. Впоследствии поселок станции расширялся.

Прокладка железнодорожной линии через Сарептскую волость и сооружение здесь круп- ной железнодорожной станции дали импульс к строительству в этом месте еще одного крупного объекта транспортного хозяйства - грузового порта. До конца XIX века ближайшая к Сарепте пристань находилась в 7 верстах от поселка. «Путеводитель по Волге», изданный в 1865 г., описывает ее как «маленький пароходный дебаркадер» $[5$, с. 55]. Во второй половине 1890-х гг. на берегу Волги у Сарепты началось строительство крупного грузового порта. Его сооружало то же Общество Владикавказской железной дороги. Для строительства порта у сарептского сельского общества было отчуждено вдоль берега 1410 десятин земли (около 1537 га) за 559724 руб. [9, л. 176]. Порт был сооружен у мелководного рукава Волги между ее правым берегом и двумя островами - Малым Сарпинским и Малым Займищем. Между островами и берегом была построена дамба; таким образом образовался затон, удобный для стоянки судов [6, с. 99].

Порт включил в себя следующие сооружения:

- нефтяная пристань: 4 резервуара на 150 тыс. пудов каждый;

- плавучая станция на железной барже с паровыми котлами, двумя насосами, устройством для нефтяного отопления;

- верхняя станция (на берегу) с тем же оборудованием в каменном здании;

- керосинопровод;

- сооружение для складирования железа в виде открытой платформы с каменными стенами;

- сооружение для хранения рыбы в виде двух крытых каменных пакгаузов;

- соляная пристань с солемолкой и амбаром площадью 200 кв. саженей;

- хлебная пристань: железная баржа под зерноподъем, галерея с транспортерами от баржи до элеватора, элеваторная башня с механическим оборудованием, два 2-этажных каменных амбара на 300 тыс. пудов каждый, соединительная галерея между амбаром и элеваторной башней;

- лесная пристань с самокатными вагонетками для леса, наклонной плоскостью для подъема леса с двигателем, ручными вагонетками для транспортировки бревен, узкоколейными путями;

- пассажирская пристань. 
При строительстве порта были проведены работы по засыпке оврагов, укреплению берега затона, дноуглубительные работы. От порта до станции Сарепта была проведена железнодорожная ветка. Расходы по сооружению порта составили 4249370 руб. [9, л. 159].

Сарептский порт начал действовать в 1901 году. Порт и железнодорожная станция представляли собой единый транспортный узел, который обеспечивал связь центральных районов страны, Прикамья, каспийского региона, Кубани и Северного Кавказа. Наибольшую долю в грузообороте железной дороги и порта до Первой мировой войны составляли лесные товары (строительные материалы, поделочное дерево, клепка), причем проходящие через станцию и порт объемы этих товаров стабильно росли. В 1905 г. из Сарепты было отправлено 588 вагонов леса, а в 1912 г. - уже около 6000 вагонов с 5,5 млн пудов [6, с. 100]. Второе место в грузообороте станции и порта занимали нефтепродукты (главным образом керосин); на третьем месте были руда и уголь; четвертое место занимала сельскохозяйственная продукция (овощи и фрукты, зерно), а также рыба [4, с. 21]. Прибывающий из центральных районов Прикамья водным путем лес далее по железной дороге отправлялся на Кубань. В обратном направлении двигалось зерно. Нефтепродукты, доставляемые по Волге из Каспия, перегружались на железную дорогу и отправлялись в центральный промышленный район. В 1913 г. станция Сарепта отправила более 9 млн пудов грузов [6, с. 100].

Строительство железной дороги и порта дали импульс развитию лесопильного и деревообрабатывающего производств в Сарептской волости. Упоминавшийся выше лесопильный завод Бауэров в Сарепте со второй половины 1890-х гг. начал быстро расширять производство и к 1910 г. превратился в одно из крупнейших предприятий поселка наряду с горчичным заводом фирмы «Наследники И.К. Глич». Число рабочих на заводе выросло с 28 человек в 1894 г. до 70 человек в 1911 г., а годовой оборот достиг 14 тыс. руб. [8, л. 36]. Продукция - доски, дранка, паковочные ящики - продавалась в Сарепте, в окрестных деревнях, вывозилась по Волге в Астрахань, а по железной дороге на Кавказ. Сырье - сосновые, еловые бревна - поступало по Волге с верховьев реки. На рубеже XIX-XX вв. в волости появилось еще несколько лесопильных заводов. Один из них был перенесен заводчиком В.Г. Рудаковым из Светлого Яра к Сарептскому порту. Другие лесопилки, построенные в 1900-х гг. на берегу Волги в районе порта, принадлежали Лившицу, Ойце, Краузе, Шарову. В 1911 г. в порту Сарепты разгрузилось 24 судна с 3285379 пудами леса на сумму 390880 рублей [4, с. 21].

Формирование в Сарептской волости крупного транспортного узла имело значительные последствия для социально-демографической характеристики этого района. На протяжении первого десятилетия XX века население Сарепты и Сарептской волости стабильно росло. Если в 1894 г. население волости составляло около 1800 человек, то в 1904 г. оно выросло до 2231 , а в 1912 г. составляло уже около 3186 человек $[13$, л. 38]. Прирост населения происходил главным образом за счет поселка железнодорожников станции Сарепта. К началу Первой мировой войны в поселке железнодорожников проживало 552 рабочих и служащих, а вместе с их семьями население поселка составляло свыше 1500 человек [11, л. 32-33]. В 3 верстах от Сарепты, таким образом, на рубеже XIX-XX вв. возник крупный по меркам волости населенный пункт, имевший развитую социальную инфраструктуру. Именно в то время начались застройка и заселение участка вдоль Волги, который и в настоящее время носит неофициальное название «поселок станции Сарепта».

В числе рабочих и служащих станции были три жителя Сарепты, представители одной семьи: Циг Иван Васильевич (машинист, мастер), Циг Александр Иванович (машинист) и Циг Роберт Иванович (смотритель зданий). Подавляющее же большинство рабочих и служащих станции и депо составляли приезжие. Часть служащих переехала в Сарептскую волость из Владикавказа, где находилось правление железной дороги. В основном же рабочие станции и депо происходили из самых разных регионов Российской империи: из Царицына, Астраханской, Тамбовской, Орловской губерний, Малороссии, Царства Польского и др. Их появление, вместе с рабочими сарептского порта и новых лесопильных заводов, привело к резкому росту численности пролетариата в Сарептской волости, который впоследствии сыграл большую роль в революционных событиях в этом районе. 
Таким образом, прокладка через территорию Сарептской волости железной дороги, строительство станции и порта оказали существенное влияние на социально-экономическую характеристику волости. Если раньше центром экономической жизни волости был ее административный центр Сарепта с преобладающими в ней мелкими полукустарными производствами, то к началу Первой мировой войны экономический центр волости переместился к железнодорожной станции и грузовому порту, причем хозяйственное значение этих предприятий выходило далеко за пределы и Сарептской волости, и Саратовской губернии. Строительство железнодорожной станции и порта также существенным образом отразились на социально-демографической характеристике района. Помимо увеличения населения Сарептской волости более чем в 1,5 раза с 1894 по 1912 г., появление двух крупных предприятий привело к значительному росту доли пролетариата в социальном составе населения волости. Это было началом формирования промышленного района, который в будущем составит южную индустриальную часть Сталинграда - Волгограда.

\section{ПРИМЕЧАНИЕ}

${ }^{1}$ Исследование выполнено при финансовой поддержке РГНФ. Проект «Трансформация религиозной общины Сарепта в городской район г. Сталинграда, 1877-1937 гг.» № 15-11-34004.

\section{СПИСОК ЛИТЕРАТУРЫ}

1. Альбом исполнительных чертежей и видов пристаней на р. Волге при станции Сарепта. - Владикавказ : Изд-во Общества Владикавказской железной дороги, 1903. - 11 с.

2. Бюллетень оценочно-статистического отделения Саратовской губернской земской управы. Саратов : Земская типография, 1880. - 42 с.

3. Велицын, А. А. Немцы в России. Очерки исторического развития и настоящего положения немецких колоний на юге и востоке России / А. А. Велицын. - СПб. : Товарищество «Общественная польза», 1893. - 282 с.

4. Весь Царицын : справочник по городу Царицыну и Царицынскому уезду. - Царицын : Издание Товарищества «Царицынская мысль», 1911. $164 \mathrm{c}$.
5. Кучин, Я. П. Путеводитель по Волге между Нижним и Астраханью / Я. П. Кучин. - Саратов : Типография Саратовского Справочного листка, $1865 .-277 \mathrm{c}$.

6. Луночкин, А. В. Владикавказская железная дорога и экономическое развитие окрестностей Царицына (конец XIX - начало XX века) / А. В. Луночкин // Вестник Волгоградского государственного университета. Серия 4, История. Регионоведение. Международные отношения. - 2010. - Вып. 2. C. 97-104. -DOI: 10.15688/jvolsu4.2010.2.13.

7. Медведев, В. Н. Миграционные процессы населения Сарепты. Вторая половина XVIII - середина XIX вв. / В. Н. Медведев // Сарепта. Историкоэтнографический вестник. - Вып. 3. - Волгоград : МИРИА, 2007.-С. 92-126.

8. Переписка с начальником Саратовского губернского жандармского управления о количестве членов Союза русского народа, списках состоящих под нелегальным надзором и по другим вопросам. 2 января 1907 - 28 февраля 1908 г. // Государственный архив Волгоградской области (ГАВО). - Ф. И-6. - Оп. 1. - Д. 129.

9. Планы и исполнительные чертежи станции Сарепта и Сарептского порта, 1895 - 1902 гг. // Государственный архив Ростовской области (ГАРО).Ф. 26. - Оп. 5. - Д. 156.

10. Сарепта: история успеха / А. В. Курышев, С. Н. Лосицкий, А. А. Максимов, В. Н. Медведев ; науч. ред. И. О. Тюменцев. - Волгоград : Издатель, 2013. $-272 \mathrm{c}$.

11. Сведения о сельских обществах, заводах, фабриках, лесах, составе станов, использовании труда малолетних на предприятиях гор. Царицына и по другим вопросам, 2 января - 31 декабря 1913 г. // ГАВО. -Ф. 37. - Оп. 1. - Д. 696.

12. Сведения о числе населенных мест и душ по Царицынскому уезду, 1894 г. // ГАВО. - Ф. И-342. Оп. 1. - Д. 8.

13. Списки населенных пунктов Царицынского уезда с указанием количества жителей, переписка с Саратовским губернским жандармским управлением о политической благонадежности и по наблюдению, 13 марта - 15 декабря 1914 г. // ГАВО. Ф. И-6. - Оп. 1. - Д. 384.

\section{REFERENCES}

1. Albom ispolnitelnykh chertezhey $i$ vidov pristaney na $r$. Volge pri stantsii Sarepta [Album of Drawings and Wharfs Designs on the Volga River at the Sarepta Railway Station]. Vladikavkaz, Izd-vo Obshchestva Vladikavkazskoy zheleznoy dorogi, 1903.11 p.

2. Byulleten otsenochno-statisticheskogo otdeleniya Saratovskoy gubernskoy zemskoy upravy 


\section{РЕГИОНОВЕДЕНИЕ}

[Bulletin of the Statistical Department of the Zemstvo (District Councils) Administration of the Saratov Gubernia]. Saratov, Zemskaya tipografiya Publ., 1880. 42 p.

3. Velitsyn A.A. Nemtsy v Rossii. Ocherki istoricheskogo razvitiya i nastoyaschego polozheniya nemetskikh koloniy na yuge i vostoke Rossii [Germans in Russia. Essays on Historical Development and the Present Condition of the German Settlements in the South and East of Russia]. Saint Petersburg, Tovarishchestvo “Obshchestvennaya polza" Publ., 1893.282 p.

4. Ves Tsaritsyn. Spravochnik po gorodu Tsaritsynu $i$ Tsaritsynskomu uyezdu [All Tsaritsyn. A Handbook on Tsaritsyn and Tsaritsyn District]. Tsaritsyn, Tovarishchestvo "Tsaritsynskaya mysl" Publ., 1911. 164 p.

5. Kuchin Ya.P. Putevoditel po Volge mezhdu Nizhnim i Astrakhanyu [A Guide to the Volga From Nizhny Novgorod to Astrakhan]. Saratov, Tipografiya Saratovskogo Spravochnogo listka, 1865. 277 p.

6. Lunochkin A.V. Vladikavkazskaya zheleznaya doroga i ekonomicheskoe razvitie okrestnostey Tsaritsyna (konets 19-nachalo20 veka) [The Vladikavkaz Railway and Economic Development of the Tsaritsyn Vicinities (From the End of the 19th to the Beginning of the 20th Centuries)]. Vestnik Volgogradskogo gosudarstvennogo universiteta. Seriya 4, Istoriya. Regionovedenie. Mezhdunarodnye otnosheniya [Science Journal of Volgograd State University. History. Area Studies. International Relations], 2010, iss. 2, pp. 97-104.

7. Medvedev V.N. Migratsionniye protsessy naseleniya Sarepty. Vtoraya polovina 18 - seredina 19 vv. [Migrations of Sarepta Population. The Second Half of the 18th Century and the First Half of the 19th Century]. Sarepta. Istoriko-etnograficheskiy vestnik, 2007, iss. 3, pp. 92-126.

8. Perepiska s nachalnikom Saratovskogo gubernskogo zhandarmskogo upravleniya o kolichestve chlenov Soyuza russkogo naroda, spiskakh sostoyashchikh pod nelegalnym nadzorom i po drugim voprosam. 2 yanvarya 1907 - 28 fevralya 1908 g. [Correspondence with Head of the Saratov Gubernia
Police Department on the Number of Members of the Russian People Union, on Registers of Those Under Police Surveillance, and on Other Matters. January 2, 1907-February 28, 1908]. Gosudarstvenny arkhiv Volgogradskoy oblasti [The State Archive of the Volgograd Region], F. I-6, Op. 1, D. 129.

9. Plany i ispolnitelnye chertezhi stantsii Sarepta i Sareptskogo porta. $1895-1902$ gg. [Drawings of the Sarepta Station and Sarepta Port. 1895-1902]. Gosudarstvennyy arkhiv Rostovskoy oblasti [The State Archive of the Rostov Region], F. 26, Op. 5, D. 156.

10. Kuryshev A.V., Lositskiy S.N., Maksimov A.A., Medvedev V.N. Sarepta: istoriya uspekha [Sarepta: a History of Success]. Volgograd, Izdatel Publ., 2013. 272 p.

11. Svedeniya o selskikh obshchestvakh, zavodakh, fabrikakh, lesakh, sostave stanov, ispolzovanii truda maloletnikh na predpriyatiyakh gor. Tsaritsyna i podrugim voprosam. 2 yanvarya - 31 dekabrya $1913 \mathrm{~g}$. [Information on Village Communities, Factories, Woods, on Using Juvenile Labour at Tsaritsyn Factories, and on Other Matters. December 31, 1913- January 2, 1913]. Gosudarstvenny arkhiv Volgogradskoy oblasti [The State Archive of the Volgograd Region], F. 37, Op. 1, D. 696.

12. Svedeniya o chisle naselennykh mest i dush po Tsaritsynskomu uezdu. $1894 \mathrm{~g}$. [Information on the Number of Inhabited Locations and Population of Tsaritsyn District. 1894]. Gosudarstvenny arkhiv Volgogradskoy oblasti [The State Archive of the Volgograd Region], F. I-342, Op. 1, D. 8.

13. Spiski naselennykh punktov Tsaritsynskogo uezda s ukazaniem kolichestva zhiteley, perepiska s Saratovskim gubernskim zhandarmskim upravleniem o politicheskoy blagonadezhnosti i po nablyudeniyu. 13 marta - 15 dekabrya 1914 g. [Lists of Inhabited Locations of Tsaritsyn District With Specification of Population Numbers; Correspondence With the Saratov Gubernia Police Department on Political Loyalty and on Police Surveillance. 13 March-15 December 1914]. Gosudarstvenny arkhiv Volgogradskoy oblasti [The State Archive of the Volgograd Region], F. I-6, Op. 1, D. 384.

\section{Information About the Author}

Aleksandr E. Parfenov, Candidate of Sciences (Economics), Head of Department of History and Ethnography, Historical, Ethnographic, and Architectural Museum-Reserve "Old Sarepta", Izobilnaya St., 10, 400026 Volgograd, Russian Federation, nauka.sarepta@mail.ru.

\section{Информация об авторе}

Александр Евгеньевич Парфенов, кандидат экономических наук, начальник отдела истории и этнографии Историко-этнографического и архитектурного музея-заповедника «Старая Сарепта», ул. Изобильная, 10, 400026 Волгоград, Российская Федерация, nauka.sarepta@mail.ru. 